\title{
TFC - O DESENVOLVIMENTO DE UMA FONTE TIPOGRÁFICA DIGITAL COMO FERRAMENTA DE ESTUDO DE CALIGRAFIA
}

\author{
Carlos Eduardo Brito Novais (Discente)/UFC \\ Solange Galvão Coutinho (Orientadora)/UFPE
}

\section{RESUMO}

Um formato comum para o estudo da caligrafia é através de lâminas de estudo. Apesar de consolidado, observa-se problemas e a possibilidade de melhorias. Este trabalho apresenta o processo de desenvolvimento da TFC - Foundational Hand, uma fonte tipográfica digital que tem como objetivo auxiliar no estudo da caligrafia através da construção de lâminas de estudo customizadas. A pesquisa foi desenvolvida em duas etapas, a primeira no Brasil e a segunda na Inglaterra e Portugal, como um dos produtos do doutorado, em curso, de Carlos Eduardo Novaisi. A fonte foi disponibilizada gratuitamente em quatro versões e os resultados dos testes finais, bem como problemas e desdobramentos são apresentados ao final deste artigo.

Palavras-chave: Caligrafia; Design de Tipos; Design da Informação.

\section{Fundamentação Teórica}

\section{A evolução das instruções em manuais de escrita}

Considerado o primeiro manual de escrita, La Operina foi publicado em 1522 por Ludovico degli Arrighi (CLAYTON, 1999). A publicação é um marco de uma reorganização laboral entre os especialistas em escrita. Em meados do século XV, a introdução da impressão por tipos móveis, atribuída a Gutenberg, desfez todo um mercado existente de cópia de livros (MEGGS; PURVIS, 2009). O impacto causado propiciou um forte crescimento comercial e urbano que levou a proliferação de universidades e aumento da demanda por conhecimento, inclusive o de escrever (FETTER, 2012). La operina, da Imparare di scriuere littera Cancellarescha (A pequena obra, para aprender a escrever a letra Chancelaresca) surge nesse contexto. Nela, as orientações sobre como as letras são criadas são expressas por escrito (figura 1).

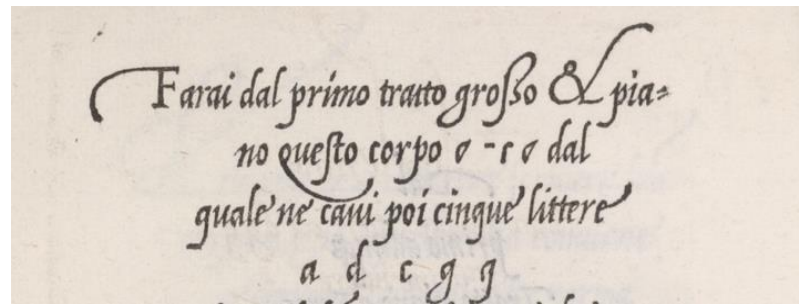

Figura 1. Trecho da página 06 da obra Operina Fonte: Arrighi (1522). 
Um exemplo desse tipo de orientação pode ser observado na página 06 da obra (figura1). Nela, lê-se as orientações "a partir do primeiro traço, grosso e curto, faça esta forma ' $O-r{ }^{\prime}$ ' da qual você obtem cinco letras a $\mathrm{d}$ c $\mathrm{g} \mathrm{q}^{\prime \prime i i}$.

Este modelo de orientação perdurou até o final do século XVIII, quando John Jenkins publica The Art of Writing (1813) (CLAYTON, 1999). No livro, originalmente publicidado em 1791, Jenkings reduz o alfabeto a cerca de seis traços aos quais o estudante deveria compreender com o núcleo formativo do modelo antes de buscar sua reprodução. Na figura 2, é possível observar como o autor apresenta os seis traços básicos do modelo caligráfico, bem como as combinações necessárias para a formação da letra " $A$ " capitular.
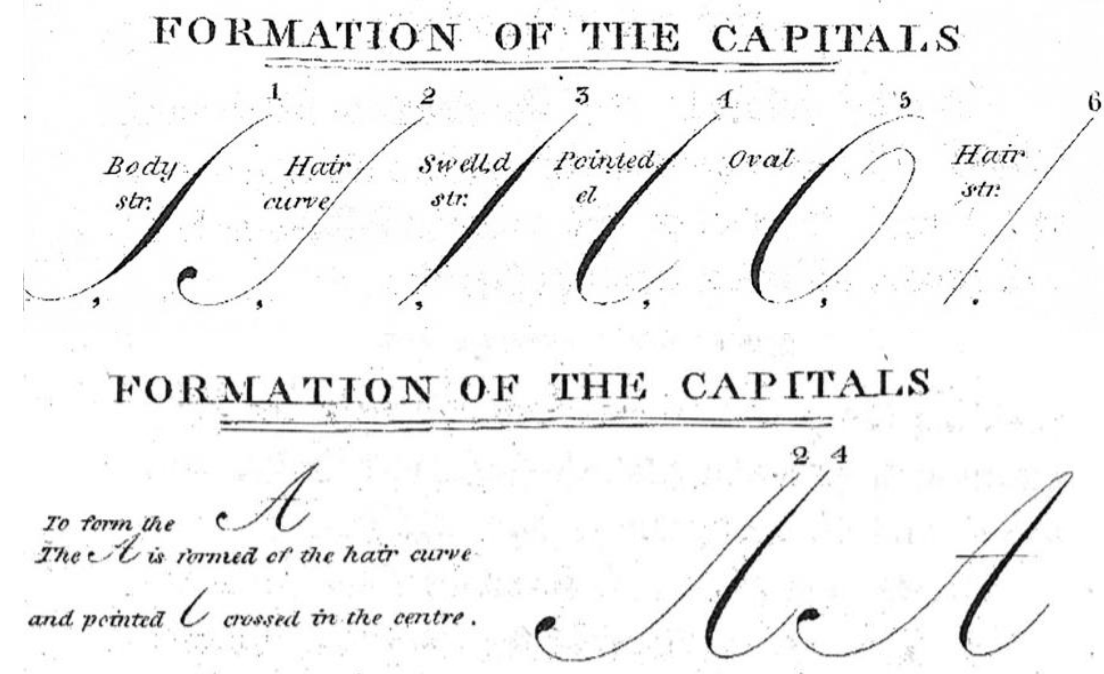

Figura 2: Trechos das páginas 36 e 38 da obra The Art of Writing Fonte: Jenkins (1813). Adaptado pelo autor

Outros modelos de ensino foram propostos e entraram em uso, tais como o modelo Spenceriano, o método Palmer, a escrita vertical, entre outros (CLAYTON, 1999; FETTER, 2012). A análise de tais modelos, todavia mostra-se mais frutífera quando são estudados para o ensino de escrita. Em caligrafia histórica (LOAIZA; VALENCIA; ARIAS, 2010), o ensino por decomposição de formas tornouse o modelo mais comumente encontrado em livros e manuais (BENNETT, 2007; BUZIAK, 2011; ENGELBRECHT, 2008; GOFFE; RAVENSCROFT, 1999; HARRIS, 2003, 2013; MARSH, 1996; MEDIAVILLA, 2005; NEWHALL, 1989; PRINCE, 1982; SASSOON, 1995; WADDINGTON, 1996).

\section{Estrutura das lâminas de estudo de caligrafia}

Novais, Oliveira e Coutinho (2019) compreendem as lâminas de trabalho de caligrafia como Sequências Pictóricas de Procedimento - SPPs (SPINILLO, 2000). Os autores apresentam um 
framework para análise das sequências de desenvolvimento de letras para a caligrafia escolar e também a caligrafia histórica (LOAIZA; VALENCIA; ARIAS, 2010).

Observa-se que, ao longo dos séculos, uma evolução que leva à um modelo procedimental complexo e refinado, onde as informações do desenvolvimento das letras vão além da simples orientação do ductus caligráfico iii. Para isso, são utilizados recursos como rótulos, legendas e dispositivos simbólicos tais como setas, cores e imagens ilustrativas (figura 3 ).

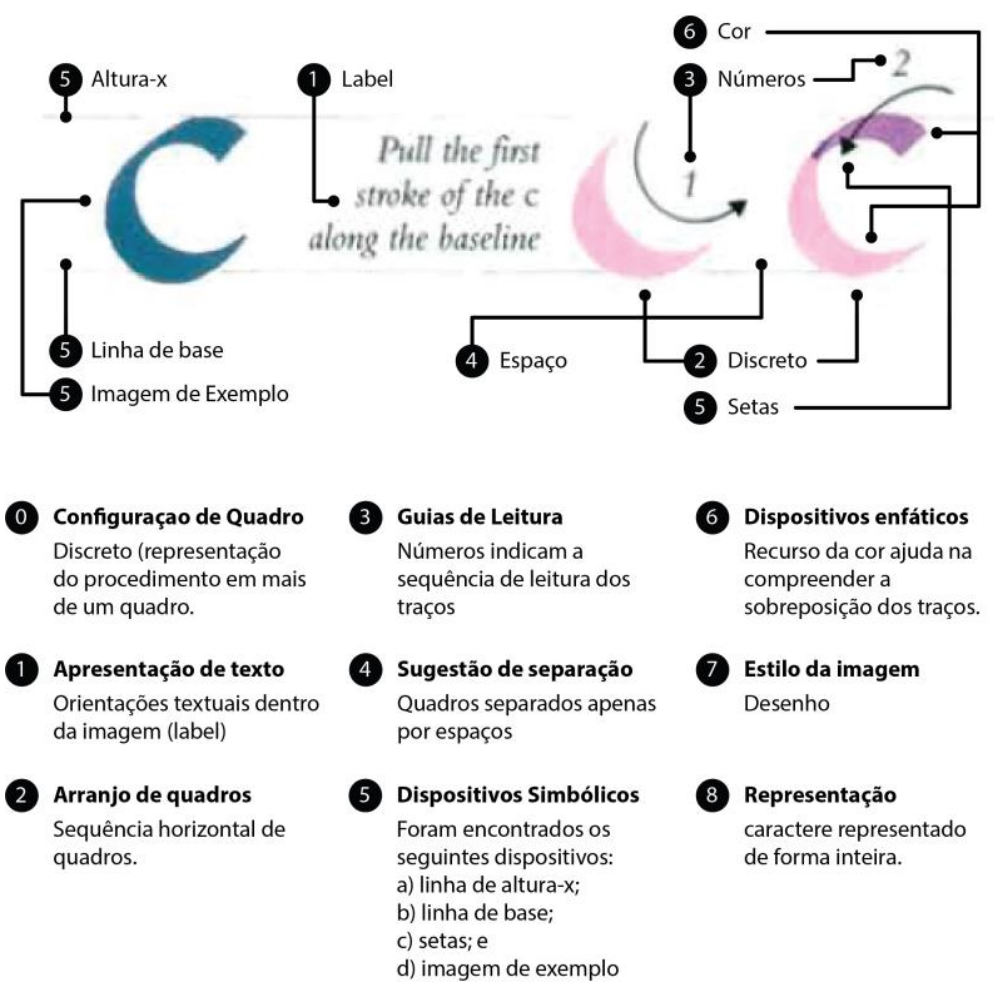

Figura 3. Análise do ductus do caractere "c" de um modelo caligráfico histórico.

Fonte: Novais, Oliveira e Coutinho (2019).

Vale ressaltar que a complexidade apresentada acima é apenas para uma letra. Uma lâmina de estudo de um modelo caligráfico costuma apresentar todas as letras de uma única vez, resultando em um sistema extremamente sofisticado e que consegue comportar um número elevado de informações. Um exemplo disso é visto em Harris (2003). O autor apresenta lâminas de estudo de um modelo cujas informações de desenvolvimento se estendem por duas páginas. Na primeira, são apresentadas informações gerais, enquanto a segunda parte apresenta informações mais específicas (figura 4). 


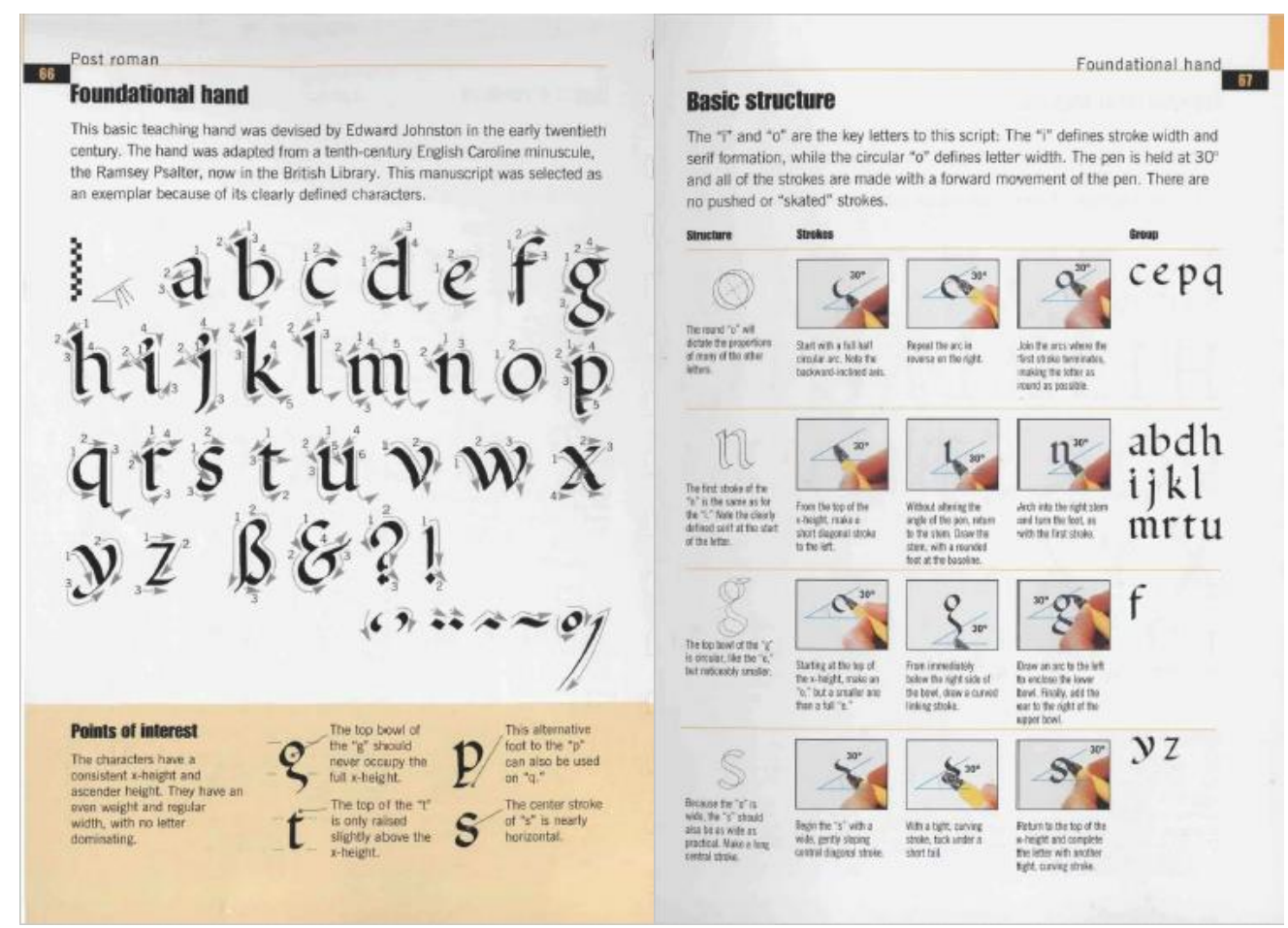

Figura 4. Exemplo de lâminas de estudo.

Fonte: Harris (2003, p. 66,67).

Este tipo de orientação pode ser encontrados em diversas referências com mais ou menos alterações (BENNETT, 2007; BUZIAK, 2011; GAUTHIER, 2010; HARRIS, 2013; MEDIAVILLA, 2005; NEWHALL, 1989; SASSOON, 1995).

\section{Problemas no uso de lâminas}

Apesar de amplamente adotado e da sofisticação alcançada, observou-se que o estudo através de lâminas possui alguns problemas que podem ser explorados para uma melhor experiência educacional. Entre eles, Sassoon (2000) destaca a dificuldade de estudantes no desenvolvimento de traços verticais e do espaçamento entre letras. Além disso, observou-se empiricamente uma dificuldade na compreensão espacial especialmente na execução de traços curvos.

\section{Métodos e procedimentos}

A pesquisa debruçou-se sobre a possibilidade do desenvolvimento de lâminas de estudo customizadas. Neste sentido, as instruções deveriam ser apresentadas no tamanho específico da pena utilizada pelo estudante e apresentando somente a informação necessária. Compreendeu-se que a o desenvolvimento de uma fonte tipográfica poderia uma saída viável para o problema.

Assim, o primeiro passo do estudo foi uma pesquisa bibliográfica e documental para estabelecer o estado da arte sobre o tema. A participação do pesquisador na conferência internacional da 
Associação Internacional de Tipografia, ATypl, em São Paulo, 2015, permitiu ao mesmo a aplicação de entrevistas informais com calígrafos e designers de tipo, explorando o tema e colhendo sugestões para o projeto.

\section{Desenvolvimento da primeira versão}

A primeira versão da TFC foi desenvolvida entre os anos de 2015 e 2017. O estilo selecionado foi o fundamental, desenvolvido por Edward Johnston com o objetivo de ser um modelo com construção baseada na combinação de poucos traços modulares. As etapas do desenvolvimento da primeira versão são apresentadas nos próximos tópicos.

\section{Estabelecendo uma relação direta entre medidas}

O corpo iv de um modelo caligráfico é dado em uma medida de proporcionalidade, as larguras de pena. É comumente apresentado na forma de quadrados empilhados, onde cada quadrado representa uma largura de pena. Na imagem a seguir, a altura do corpo da letra é de onze larguras de pena (figura 5).

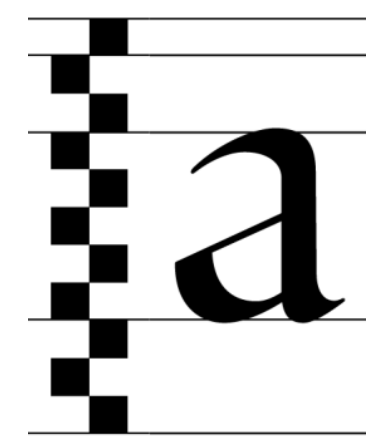

Figura 5. Indicação de altura de letra utilizando altura de penas. Fonte: Desenvolvido pelo autor.

O tamanho de uma fonte em um software, por sua vez, é apresentado em desktop publishing point (DTP). Neste sentido, 1 DTP é equivalente a 0.3527 mm (BUGGY, 2018; LUPTON, 2006). A solução para criar uma relação compreensível entre o tamanho da fonte e a largura de pena passou pela subversão do uso da métrica em softwares para o desenvolvimento de fontes digitais, a UMP, ou unidades por eme (HENESTROSA, 2014). Neste tipo de medida, o corpo da fonte, eme, é subdividido em unidades e, consequentemente, o desenho vetorial é desenvolvido neste espaço de altura (figura 6). 


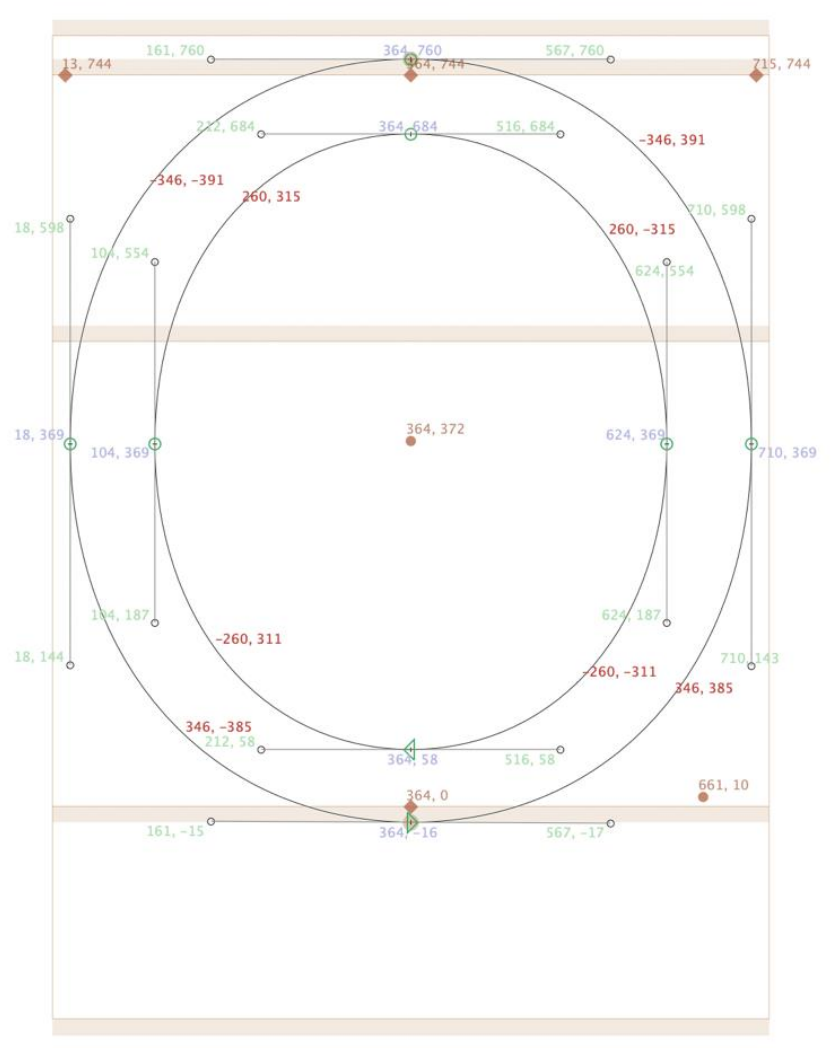

Figura 6. Posicionamento de pontos de controle em uma letra desenvolvida em 1000 UPMs. Fonte: Desenvolvido pelo autor.

Em uma fonte com resolução de 1000 UPMs, um símbolo de 1000 UPMs de altura, em um software de texto quando definido em 1 ponto DTP, teria uma impressão com 0,3527 mm. Utilizou-se o conceito matemático da regra de três composta para descobrir que para que a impressão de uma letra no tamanho de $1 \mathrm{~mm}$ sem alterações no software, o glifo deveria ter 283,527 UPMs (figura 7). Observando tamanho de penas, viu-se que os valores seriam muito baixos e dependentes do uso de vírgula. Assim, decidiu-se que o glifo seria 10 vezes maior que o calculado, chegando ao valor de 2.835,27 UPMS.

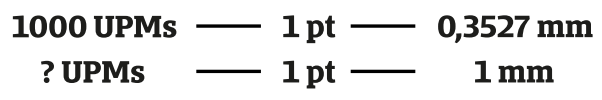

Figura 7. Estrutura da regra de três composta Fonte: Desenvolvido pelo autor.

\section{A matemática para os cálculos de traços}

Uma vez definido o tamanho do corpo de texto, era necessário calcular o valor individual de uma largura de pena. Para isso, primeiro foi realizado um estudo sobre as medidas utilizadas na representação do modelo fundamental. Foi definido que as medidas das ascendentes e descendentes seria de 3 larguras de penas cada e a altura-x seria equivalente a 4 unidades (figura 8 ). 


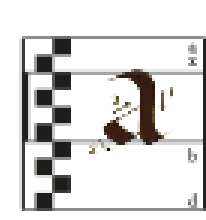

Modiulta (sooes)

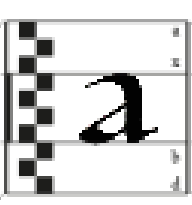

Driace (19ac)

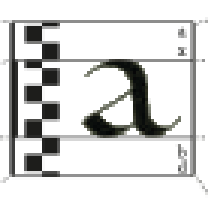

Saแน⿰冫 (29)5)

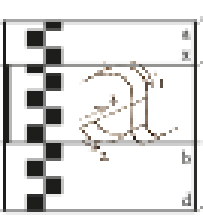

wilinges

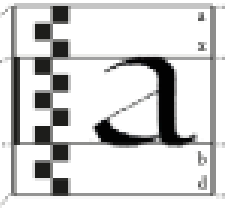

Buraett (20005)

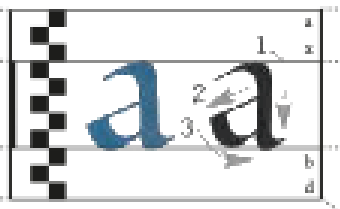

$\operatorname{Marrix}(1965,2 \mathrm{es})$

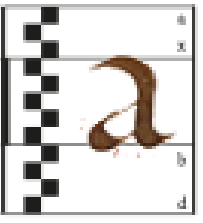

binstion (1993)

Figura 8. Comparação entre medidas da fundamental de diferentes calígrafos. Fonte: Desenvolvido pelo autor

Desta forma, uma vez definido que o corpo teria 10 larguras de pena e que este valor em UPMs equivale a 2.835, 27 UPMs, cada unidade teria o tamanho de 283,52 UPMs (figura 9).
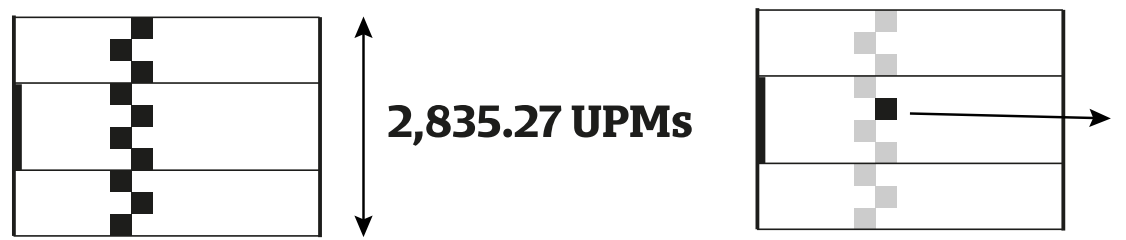

\subsection{UPMs}

Figura 9. Delimitação de tamanhos da fonte

Fonte: Desenvolvido pelo autor

Para a determinação da espessura da haste horizontal e vertical, recorreu-se às relações de um triângulo retângulo, que se aplicam ao caso do traço caligráfico. Neste sentido, a largura de pena representaria a hipotenusa do triângulo. 0 cateto 01 (c1) equivaleria à espessura do traço vertical e o segundo cateto (c2) à espessura do traço horizontal. Conhecido o ângulo de pena do modelo fundamental, $30^{\circ}$, obteve-se os valores das espessuras pelas fórmulas: $C 1=h^{*} \cos (30)$ e $C 2=h^{*}$ sen (30), expresso na figura 10.

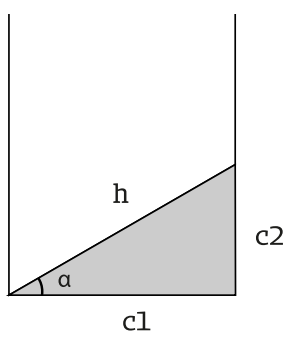

Figura 10. Análise de espessura de traço caligráfico sob uma visão da trigonometria. Fonte: Desenvolvido pelo autor.

\section{O desenho da primeira versão da família}

De posse dos valores necessários, buscou-se referências em livros e apostilas de caligrafia e no desenho do próprio pesquisador, para o desenvolvimento da primeira versão da família, finalizada em meados de 2017 (figura 11). 


\section{ABCDEFGHIJKLMNOPQR STUVWXYZabcdefgghijklmn opqrstuvwxyz0123456789\&}

Figura 11. Set de caracteres da primeira versão da TFC- Foundational Hand. Fonte: Desenvolvido pelo autor.

\section{Testes da primeira versão}

O primeiro protótipo do projeto da fonte foi colocado em teste (curso de caligrafia, utilização da fonte e grupo focal) em três cidades: Caruaru/PE, em novembro de 2017, o teste foi aplicado com sete voluntários participantes do Laboratório de Tipografia do Agreste (LTA); Recife/PE, em dezembro de 2017, cinco voluntários, estudantes da disciplina de Design de Tipos do curso de Design da UFPE; e em Fortaleza/CE, em setembro de 2018, com sete voluntários do Laboratório de Tipografia do Ceará (LTC).

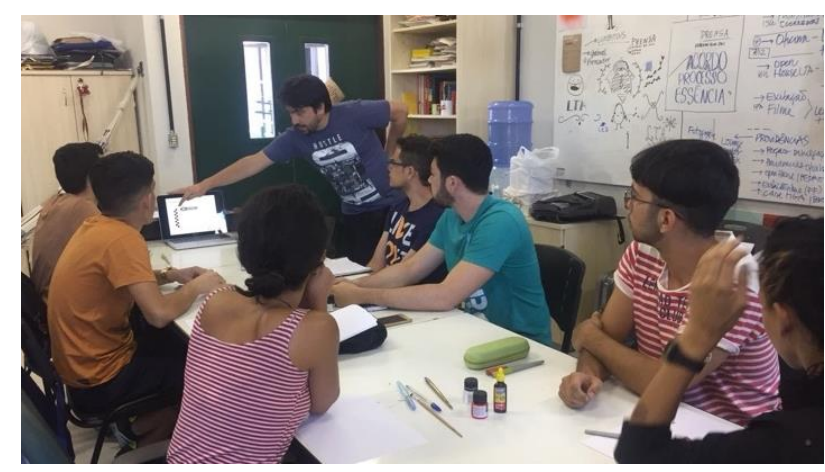

Figura 12. Aplicação de teste da TFC no Laboratório de Tipografia do Agreste, Caruaru. Fonte: Acervo do autor.

Entre as informações colhidas, observou-se a aprovação do produto, a possibilidade do uso para a composição de layouts, a necessidade de melhoria no desenho e no espaçamento do projeto.

\section{O desenvolvimento da segunda versão}

Analisados os resultados, o projeto passou por uma revisão durante o desenvolvimento das atividades de pesquisa do doutorando (bolsa sanduíche fomentada pela CAPESv), entre novembro de 2018 e setembro de 2019, junto ao Department of Typography and Graphic Communication da Universidade de Reading/Inglaterra. 
O acesso ao acervo da universidade, além da tutoria de professores especializados, permitiu o avanço do desenho do projeto e do seu espaçamento. Entre as peças e livros analisados, a mais importante foi um original da série "Winchester formal writing sheets" de 1917, em que o Edward Johnston apresenta orientações sobre como escrever utilizando o modelo fundamental (figura 13).

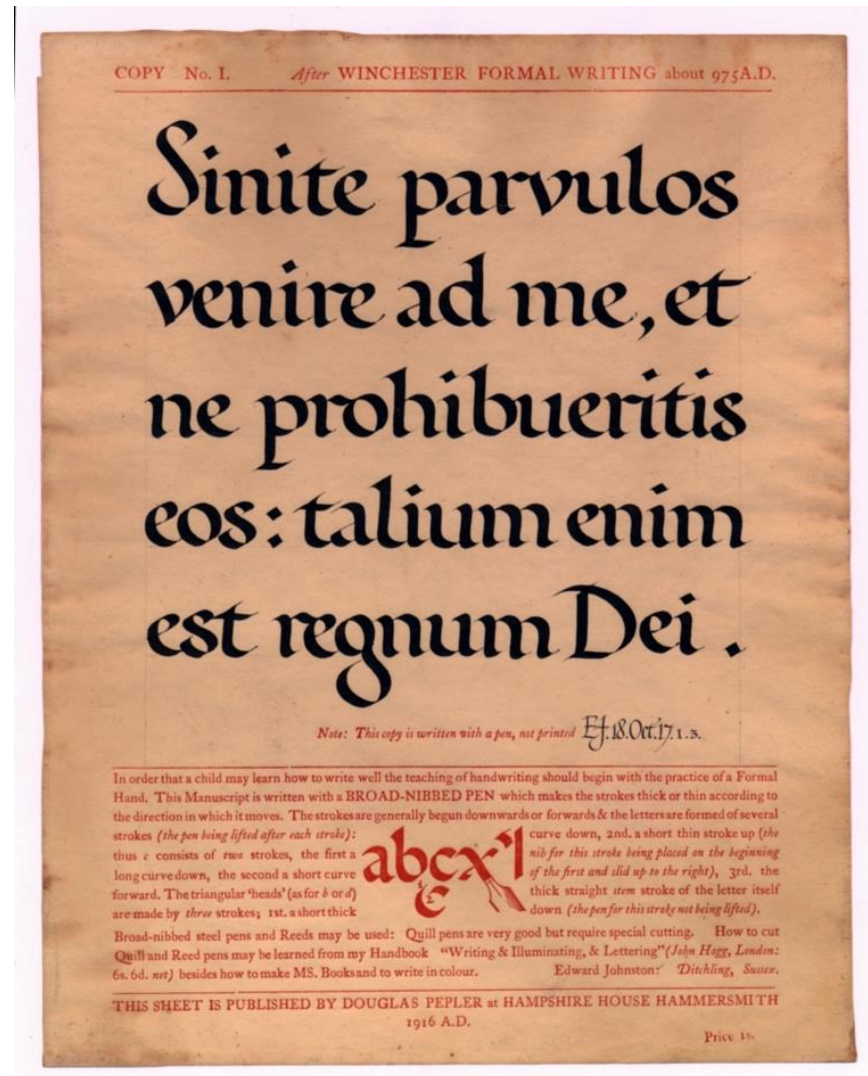

Figura 13. Winchester formal writing sheets (Edward Johnston, 1917).

Fonte: Acervo do Department of Typography and Graphic Communication da Universidade de Reading/UK.

O desenho do projeto foi alterado levando em consideração às novas referências, mas, também, a sua adequação como sistema tipográfico. Todavia, tomou-se cuidado para que qualquer alteração seguisse mantendo relação com sua execução caligráfica (figura 14).
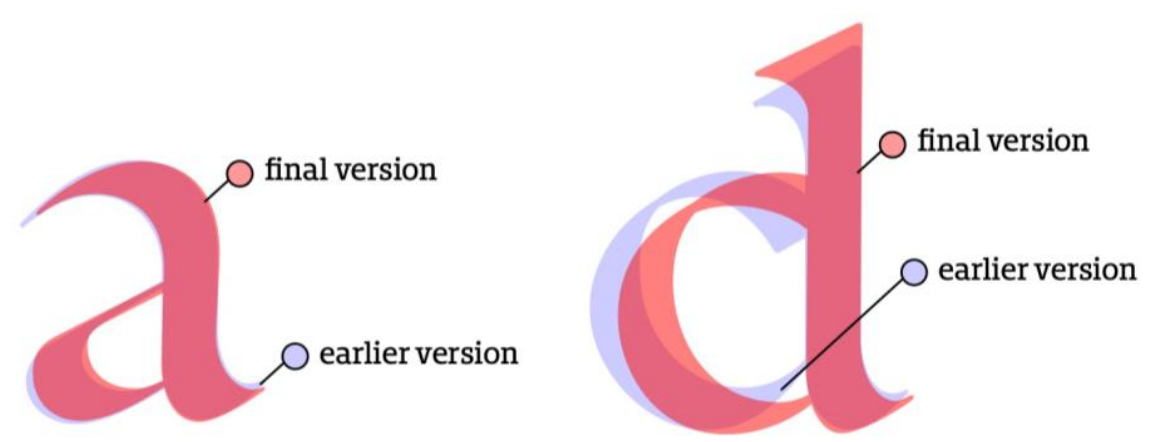

Figura 14. Exemplo de adequações tipográficas no desenho do projeto 
Fonte: Desenvolvido pelo autor.

Por fim, foi desenvolvido um estudo sobre a apresentação das informações do ductus. O uso de ornamentos internalizados nas hastes das letras tornou o resultado mais limpo, a percepção de espaço foi melhorada pensando no uso da fonte como ferramenta para o layout de peças caligráficas (figura 15).

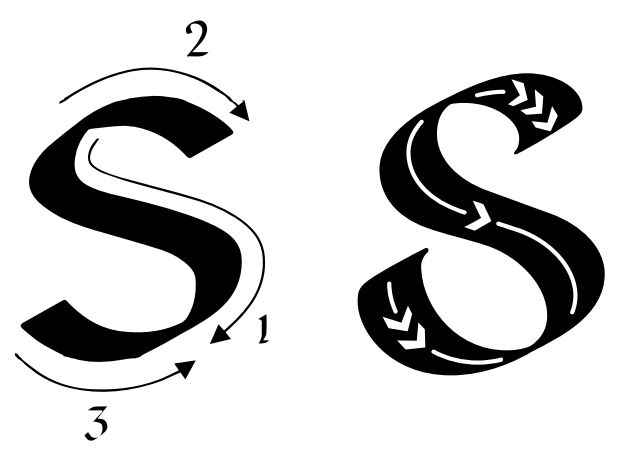

Figura 15. Alterações no design da informação através da aplicação de ornamentos Fonte: Desenvolvido pelo autor.

A nova versão da TFC foi finalizada em setembro de 2019. A família tipográfica foi desenvolvida em duas possibilidades de altura-de-x (com 4 ou 5 larguras de pena) e com a possibilidade de inclusão ou não do ductus e das linhas guias. Assim, a família foi disponibilizada gratuitamente em quatro versões. No specimem a seguir há semelhanças e particularidades entre o projeto proposto (figura 16) e o original de Johnston (figura 13).

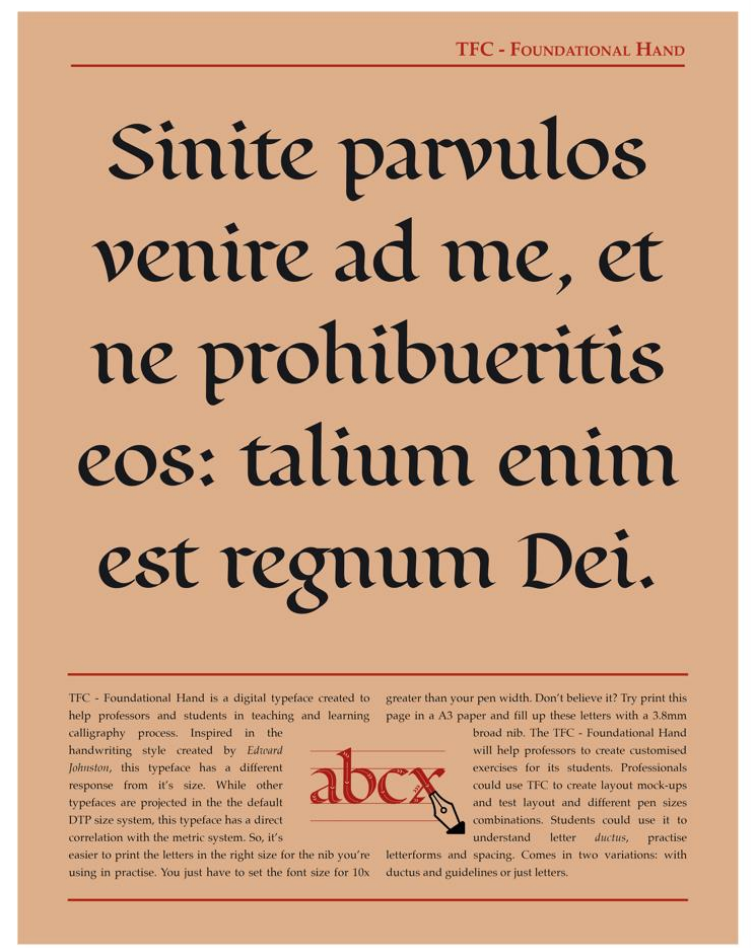


Figura 16. Type Specimen da TFC - Foundational Hand

Fonte: Desenvolvido pelo autor baseado em Johnston (1917).

Ao final do desenvolvimento desta versão, a TFC foi posta em teste novamente, desta vez, na cidade de Aveiro, Portugal, entre os dias 6 e 7 de fevereiro de 2020 (figura 17). Os voluntários recrutados através da divulgação na forma de cartazes no bloco do Departamento de Comunicação e Artes (DeCA) da Universidade de Aveiro (UA).

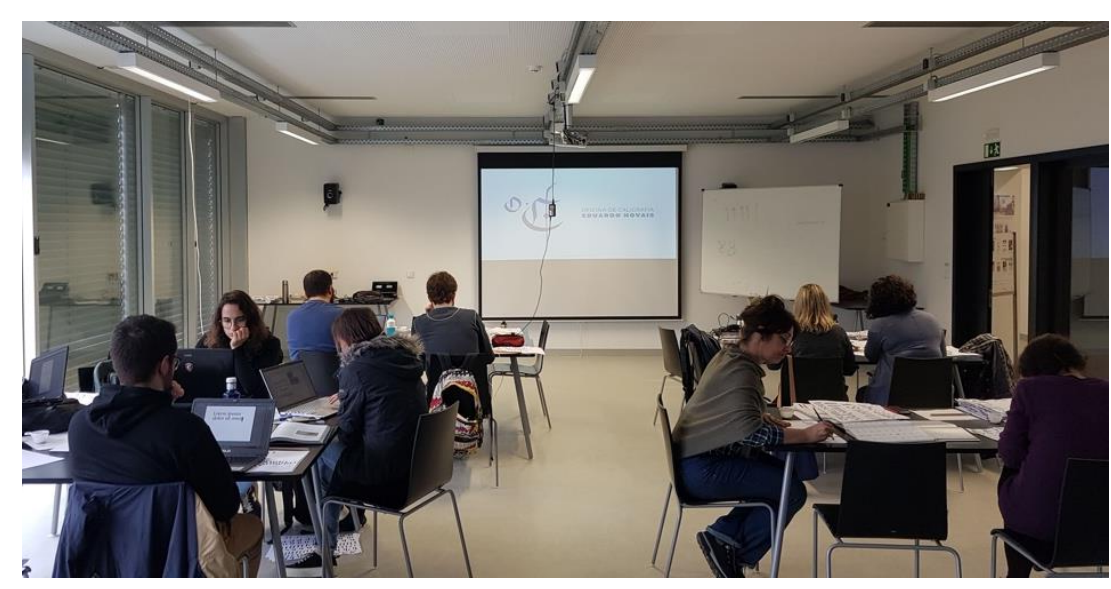

Figura 17. Aplicação de teste da TFC em Aveiro/Portugal Fonte: Acervo do autor.

Dado o número maior de participantes, as opiniões foram colhidas através de formulário. Do total de onze respondentes, todos consideraram positiva a inserção da TFC como recurso educacional.

Destes, $72 \%$ mostraram-se muito satisfeitos com o uso da fonte.

\section{Discussão}

O desenvolvimento da relação numérica compreensível entre o tamanho da fonte e do instrumento caligráfico mostrou-se desafiador. Se por um lado, obteve-se sucesso na relação; por outro, o espaço das entrelinhas acabou prejudicado. Durante a aplicação da ferramenta, foi necessário adicionar uma explicação sobre como contornar este problema. Observou-se que os valores de proporção de letra adotados por diferentes calígrafos variam. Assim, adotou-se um sistema com duas possibilidades de altura-de-x. $\mathrm{O}$ acesso ao acervo da Universidade de Reading mostrou-se crucial para o resultado. $\mathrm{O}$ feedback dos testes e dos professores consultados apontou para um uso secundário não planejado, a composição de layouts. Neste sentido, foram disponibilizadas variações da família com e sem o ductus. Observou-se uma grande aceitação do projeto final em seu teste em Aveiro. Por fim, o projeto foi apresentado em dois encontros não acadêmicos, mas de grande relevância junto à comunidade de designers de tipos e calígrafos: ATypl e DiaTipoX, ambos em 2020. 


\section{Conclusão}

A pesquisa alcançou o seu objetivo ao entregar à comunidade uma família tipográfica em quatro versões, disponível gratuitamente em http://tfc.design. Como parte da pesquisa do doutorando, a TFC foi utilizada nos experimentos para a tese (defesa prevista para dezembro de 2021).

O processo de desenvolvimento transdisciplinar envolveu áreas como a trigonometria, design da informação, informática, caligrafia e design de tipos. A ferramenta mostrou potencial de uso além do planejado, adequando-se ao planejamento de layout. Não se conseguiu ainda resolver os problemas da entrelinha. Como desdobramentos da pesquisa, podem ser desenvolvidos novos modelos caligráficos, além da adequação a tecnologias como fontes variáveis e com cores.

\section{Agradecimentos}

À Coordenação de Aperfeiçoamento de Pessoal de Nível Superior - Brasil (CAPES), aos professores Rosângela Vieira, Paula Valadares, Verônica Freitas, Fátima Finizolla e Fábio Caparica e aos voluntários do LTA (CAA UFPE), à Prof. Solange Coutinho e aos alunos da disciplina de Design de Tipos, semestre 2017.2 (Curso de Design da UFPE) e aos professores Leonardo Buggy e Lia Alcântara e aos voluntários do LTC (Design - UFC), Aos professores Gerry Leonidas e Sue Walker da Universidade de Reading (UK) e aos professores Nelson Zagalo, Gonçalo Gomes e Olinda Martins (DeCA - Universidade de Aveiro).

\section{Referências}

ARRIGHI, Ludovico degli. La operina, da imparare di scriuere littera cancellarescha. Roma. 1522 BENNETT, Jim. Calligraphy For Dummies. Indiana: Wiley, 2007.

BUGGY, Leonardo Araújo da Costa. Mecotipo: método de ensino de desenho coletivo de caracteres tipográficos. 2a. ed. Brasília: Estereográfica, 2018.

BUZIAK, Cari. Calligraphy Magic: How to Create Lettering, Knotwork, Coloring and More. Estados Unidos: North Light, 2011.

CLAYTON, Ewan. A history of learning to write. In: WILCOX, Timothy; CLAYTON, Ewan (org.). Handwriting: everyone's art. Ditchling: Edward Johnston Foundation; Ditchling Museum, 1999. p. 918. Disponível em: www.ejf.org.uk/Resources/ejhandw.pdf.

ENGELBRECHT, Lisa. Modern Calligraphy and Hand Lettering: A Mark-Making Workbook for Crafters, Cardmakers, and Journal Artists. Massachusetts: Quarry Books, 2008.

FETTER, Sandro. Modelos caligráficos na escola brasileira: uma história do Renascimento aos nossos dias. 2012. Universidade do Estado do Rio de Janeiro, [S. I.], 2012.

GAUTHIER, Jeaneen. Calligraphy 101. 1. ed. Minneapolis: Creative Publishing Int'I, 2010.

GOFFE, Gaynor; RAVENSCROFT, Anna. Taller de caligrafía. London: Könemann, 1999.

HARRIS, David. The Calligrapher's Bible: 100 Complete Alphabets and how to Draw Them. Nova lorque: Barron's, 2003. 
HARRIS, David. A arte da Caligrafia. São Paulo: Ambientes \& Costumes, 2013.

HENESTROSA, Cristóbal. Espaçamento. In: HENESTROSA, Cristóbal; MESEGUER, Laura; SCAGLIONE, José (org.). Como criar tipos: do esboço à tela. 1. ed. Brasília: Estereográica, 2014. p. 152.

JENKINS, J. The Art of Writing. Cambridge: publisher not identified, 1813.

LOAIZA, Fernando Romero; VALENCIA, Jorge Alberto Lozano; ARIAS, Rubén Darío Gutierréz. Caligrafía Expresiva, Arte y Diseño. Colômbia: Publiprint, 2010.

LUPTON, Ellen. Pensar com Tipos. São Paulo: Cosac Naify, 2006.

MARSH, Don. Calligraphy. $1^{\text {a }}$ ed. Cincinati: North Light Books, 1996.

MEDIAVILLA, Claude. Caligrafía: del signo caligráfico a la pintura abstracta. Valência: Campgràfic, 2005.

MEGGS, Philip B.; PURVIS, Alston W. História do design gráfico. 4. ed. São Paulo: Cosac Naify, 2009.

NEWHALL, Arthur. Calligraphy \& Letter Design: Learn the basics of creating elegant letter forms and discover of variety of styles and samples. Londres: Walter Foster Publishing, 1989.

NOVAIS, Carlos Eduardo Brito; OLIVEIRA, Eduardo; COUTINHO, Solange. O desenvolvimento de um framework descritivo de ductus caligráfico. In: Blucher Design Proceedings 2019, São Paulo. Anais [...]. São Paulo: Editora Blucher, 2019. p. 2419-2433. DOI: 10.5151/ped2018-3.3_ACO_55.

PRINCE, Lesley. An Introduction to Calligraphy. Birmingham: Turves Green, 1982.

SASSOON, Rosemary. The practical guide to calligraphy. New York: Mud Puddle Books, 1995.

SASSOON, Rosemary. The art and science of handwriting. Portland: Intellect, 2000.

SPINILLO, Carla Galvão. An analytical approach to procedural pictorial sequences. 2000. The University of Reading, Reading, Inglaterra, 2000.

WADDINGTON, Adrian. The Creative Calligraphy Source Book. Estados Unidos: Watson-Guptill Publications, 1996.

WELLINGTON, Irene. The foundational hand. 1947. Disponível em:

https://vads.ac.uk/digital/collection/CSC/id/3035/rec/58. Acesso em: 17 jul. 2021.

\footnotetext{
'A tese "Caligrafia para o Design de tipos: um estudo sobre o impacto de um curso de caligrafia nos conceitos de espaçamento e correlação de forma em estudantes de design de tipos" deverá ser defendida em dezembro de 2021. ii "Farai dal primo tratto grosso \& piano questo corpo " 0 " $C$ O" dal quale ne cassi poi cinque littere a d c $g$ q". tradução do autor.

iii De forma resumida, o ductus caligráfico pode ser definido como o número, ordem e direção dos traços (MEDIAVILLA, 2005).

iv O corpo da fonte é a medida que corresponde ao espaço entre os extremos das ascendentes e descendentes de um conjunto de caracteres (BUGGY, 2018).

$\checkmark$ Processo $n^{\circ} 88881.188400 / 2018-01$
} 